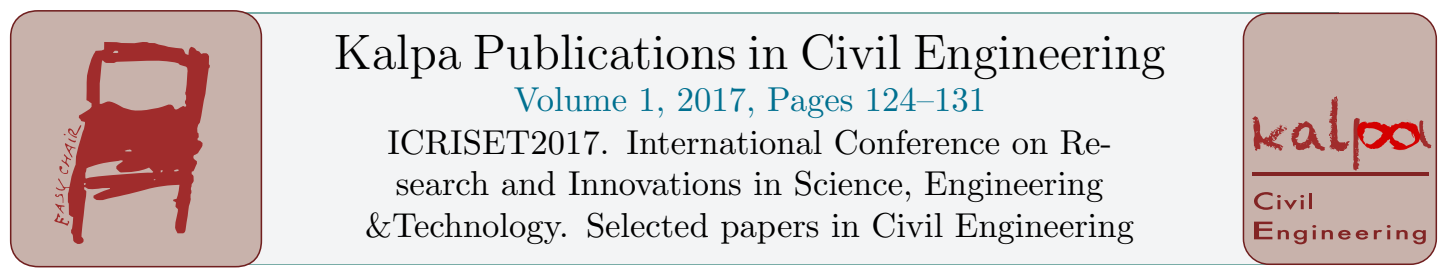

\title{
Ambient Air Quality Assessment using Air Quality Index of Delhi
}

\author{
Jay S. Patel ${ }^{1}$ Hirva U. Salvi ${ }^{2}$ and Neha R. Patel ${ }^{3}$ \\ ${ }^{1}$ EasyChair \\ ${ }^{2}$ BVM Engineering College, Gujarat, INDIA. \\ jaypatelpoly@gmail.com, hirva.salvi3015@gmail.com
}

\begin{abstract}
Urban air pollution is rapidly increasing in Indian cities. It affects the health and mental status of urban dwellers. In the present study, air pollutants data were collected for a year 2016 at 4 locations in Delhi from Central Pollution Control Board. The present study incorporates the analysis of the ambient air in Delhi city using Air Quality Index (AQI). An AQI is proposed for the city of Delhi, India for easy data interpretation and understanding of air quality. The air pollutants analyzed are Sulfur dioxide $\left(\mathrm{SO}_{2}\right)$, Nitrogen dioxide $\left(\mathrm{NO}_{2}\right)$ and Particulate matter $\left(\mathrm{PM}_{2.5}\right)$. The locations selected are Dwarka, R.K Puram, Panjabi Baugh, and Anand Vihar. The AQI were calculated using IND-AQI procedure. It has been observed that AQI's values of all four locations falls under very poor category. The overall AQI was found under very poor and sever categories. It was found that AQI values were very high during winter season and low during monsoon season. The $\mathrm{AQI}$ of $\mathrm{PM}_{2.5}$ was found exceeding the limits for all the months in each location. Thus, it is observed that $\mathrm{PM}_{2.5}$ is critical pollutant at these four locations in Delhi.
\end{abstract}

Keywords: Air Pollution, Air Quality Index, Particulate Matter $\left(\mathrm{PM}_{2.5}\right), \mathrm{SO}_{2}, \mathrm{NO}_{2}$

\section{Introduction}

Clear air is essential for the healthy life and sustainability of humans. The presence of dangerous substances in the form of particulate matters and gases in the air leads to the degradation of air quality. Anthropogenic emission such as particulate matter and various gaseous emissions are being pumped into the atmosphere.

Urban air quality is degrading at a faster rate due to combustion of fossil fuel that is used in generation of power, transportation, industrial needs and other activities. Air pollution causes a damaging effect on the physiology as well as the psychology of urban dwellers. Number of studies carried out on Indian cities showered that ambient air pollution concentrations are very high risking the life of people continuous deterioration of ambient air in cities due to urban activities along with lack of 
mitigation measures will worsen the problem in future. The pollutants responsible for adversely affecting the air quality are SPM, RSPM, $\mathrm{SO}_{2}, \mathrm{CO}$, and $\mathrm{NO}_{2}$. These pollutants exposure on a prolong time period can cause cardiovascular and respiratory disease. Delhi is among the most polluted cities of India and the world and provides a good choice for study. The air quality reports published by central pollution control board has showed the presence of various pollutants exceeding the limits over a years, the report published by world health organization indicated the rise in deaths due to air pollution in Delhi. Number of steps taken the part under the observation of Supreme Court of India including switching over a CNG introduction of batter standard of fuel, intermittent closer of power plant located in Delhi closing of air polluting industries; odd-ever plan for playing private cars on road. In spite of all these, the level of air pollution is increasing due to rapid population growth and expanding industrial activities in and around the Delhi. The city has highest registered motor vehicle in India more than other cities such as Mumbai, Kolkata and Chennai.

Air quality monitoring in Delhi carried out at various localities. The monitoring is carried out by various organizations such as central pollution control board, Delhi pollution control committee (DPCC) and system of air quality and whether forecasting and research (SAFAR) of Indian institute of tropical meteorology (IITM), Pune the monitoring data provides a large volume of data that do not provide a clear picture to policy maker or to a common man regarding the status of air quality in terms of how good or bad the air is? The raw data can be presented in statistical forms but become confusing for the common people. As a result, people tend to lose interest and cannot understand the state of air quality. To overcome this problem the concept of air quality index (AQI) has been developed.

In the past, some studies were carried out for air quality assessment of Delhi. The present study includes the daily averaged concentration data of air pollutants for the year 2016 based on AQI values. This IND-AQI has six categories.

\begin{tabular}{|l|l|}
\hline Category & Range \\
\hline Good & $0-50$ \\
\hline Satisfactory & $51-100$ \\
\hline Moderately Polluted & $101-200$ \\
\hline Poor & $201-300$ \\
\hline Very poor & $301-400$ \\
\hline Severe & $401-500$ \\
\hline
\end{tabular}

Table 1: Various Categories of IND-AQI (National Air Quality Index, CPCB, Oct. 2014)

\section{Air Quality Index}

AQI is a tool developed by the United States environmental protection agency (USEPA) to characterize the air quality. An AQI transforms weighted values of individual air pollution related parameters into a single number on set of numbers.

\section{Material and Methods}

\section{Study area}

Delhi is geographically located in north India at $28^{\circ} 21^{\prime} 17^{\prime \prime}$ and $28^{\circ} 53^{\prime} 00^{\prime \prime} \mathrm{N} 77^{\circ} 45^{\prime} 30^{\prime \prime}$ and $77^{\circ} 21^{\prime} 30^{\prime \prime}$ E long, spreading across and area of $1483 \mathrm{~km}^{2}$. It is administrated by central and state government. As per the census 2011, Delhi is inhabited by approximately 16.3 million people making it the second most populous city in India. 
Delhi experiences dry climate and extreme summer and winter. Delhi is four well-designed seasons. Winter (December to February), summer (March to June), Monsoon (July to September) and post monsoon (October to November), Delhi has taken various steps control the air pollution level during last decade however more efforts are required to improve the ambient air quality of Delhi.

\section{Air Quality Data}

CPCB along with DPCC and SAFAR monitors. The level of pollutants in various areas of Delhi under the national Ambient air quality-monitoring program (NAAQMP) the daily average concentration data of $\mathrm{NO}_{2}, \mathrm{SO}_{2}$ and $\mathrm{PM}_{2.5}$ were collected from the CPCB for different monitoring stations located in Figure 1 shows location of the monitoring stations.

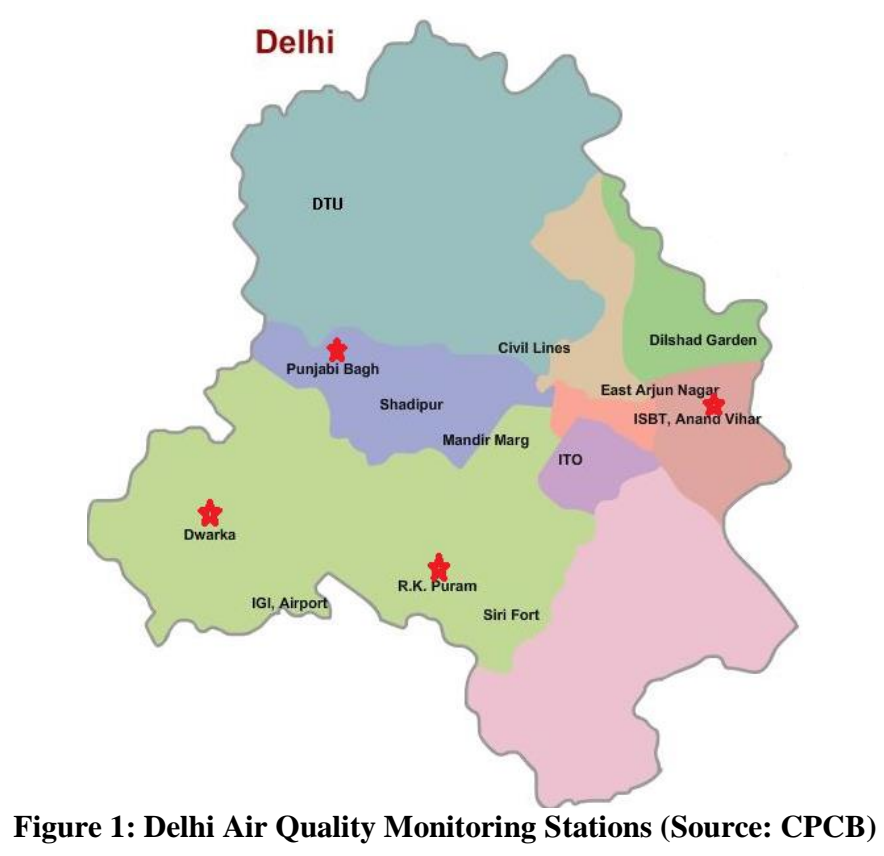

\section{AQI Development}

The sub-index values of various pollutants values calculated based on the maximum operation system of USEPA for each month of year 2016. The maximum value of sub-indices for each pollutant taken to represent overall AQI. The mathematical use for calculating the sub-indices is as follows:-:

$$
I_{p}=\left(\frac{\left(I_{H I}-I_{L O}\right.}{B_{P H I}-B_{P L O}} \times\left(C_{P}-B_{P L O}\right)\right)+I_{L O}
$$

Where, IP is the Sub-index of pollutants, $\mathrm{CP}$ is the Pollutants concentration, $\mathrm{B}_{\mathrm{PHI}}$ is the Break point concentration greater or equal to given concentration, $\mathrm{B}_{\mathrm{PLO}}$ is the Break point concentration smaller equal to given concentration, $\mathrm{I}_{\mathrm{HI}}$ is the sub-index or AQI value corresponding to $\mathrm{B}_{\mathrm{PHI}} \mathrm{I}_{\mathrm{LO}}$ is the sub index or AQI value corresponding to $\mathrm{B}_{\mathrm{PLO}}$. The table 2 shows the Linear segmented relationship for sub-index values and the corresponding pollutant concentrations that calibrated to Indian conditions. 


\begin{tabular}{|l|l|l|l|}
\hline AQI Category Range & $\begin{array}{l}\mathbf{P M}_{2.5} \\
\mathbf{( 2 4 h r s )}\end{array}$ & $\begin{array}{l}\mathbf{S O}_{\mathbf{2}} \\
\mathbf{( 2 4 h r s )}\end{array}$ & $\begin{array}{l}\mathbf{N O}_{2} \\
\mathbf{( 2 4 h r s )}\end{array}$ \\
\hline Good (0-50) & $0-30$ & $0-40$ & $0-40$ \\
\hline Satisfactory (51-100) & $31-60$ & $41-80$ & $41-80$ \\
\hline Moderately Polluted (101-200) & $61-90$ & $81-380$ & $81-180$ \\
\hline Poor (201-300) & $91-120$ & $381-800$ & $181-280$ \\
\hline Very Poor (301-400) & $121-250$ & $801-1600$ & $281-400$ \\
\hline Severe (401-500) & $>250$ & $>1600$ & $>400$ \\
\hline
\end{tabular}

Table 2: Breakpoints of various pollutants (National Air Quality Index, CPCB, Oct. 2014) (Units: $\mu \mathrm{g} / \mathrm{m}^{3}$ )

\section{Results and Discussion}

The air quality trends compared on yearly basis for all the monitoring stations:

\section{AQI analysis of different air quality monitoring stations}

In the analysis, it was observed that AQI values very widely among various stations.

\section{A. Dwarka Monitoring Station}

The study shows that maximum and minimum concentration of $\mathrm{PM}_{2.5}, \mathrm{SO}_{2}$ and $\mathrm{NO}_{2}$ are 1033.76 $\mu \mathrm{g} / \mathrm{m}^{3}$ and $40.28 \mu \mathrm{g} / \mathrm{m}^{3}, 122.64 \mu \mathrm{g} / \mathrm{m}^{3}$ and $1.46 \mu \mathrm{g} / \mathrm{m}^{3}, 108 \mu \mathrm{g} / \mathrm{m}^{3}$ and $4.22 \mu \mathrm{g} / \mathrm{m}^{3}$. The AQI values for all months except August falls under very poor category. The $\mathrm{PM}_{2.5}$ is critical pollutant at this location.

\section{B. R.K. Puram Monitoring Station}

The study shows that maximum and minimum concentration of $\mathrm{PM}_{2.5}, \mathrm{SO}_{2}$ and $\mathrm{NO}_{2}$ are 713.11 $\mu \mathrm{g} / \mathrm{m}^{3}$ and $18.55 \mu \mathrm{g} / \mathrm{m}^{3}, 317.75 \mu \mathrm{g} / \mathrm{m}^{3}$ and $4.15 \mu \mathrm{g} / \mathrm{m}^{3}, 150.17 \mu \mathrm{g} / \mathrm{m}^{3}$ and $21.72 \mu \mathrm{g} / \mathrm{m}^{3}$. The AQI values falls under very poor, Moderate, Satisfactory and Severe categories. The AQI values of July and August falls under satisfactory category. The $\mathrm{PM}_{2.5}$ is critical pollutant at this location.

\section{Punjabi Baugh Monitoring Station}

The study shows that maximum and minimum concentration of $\mathrm{PM}_{2.5}, \mathrm{SO}_{2}$ and $\mathrm{NO}_{2}$ are 783.14 $\mu \mathrm{g} / \mathrm{m}^{3}$ and $11.31 \mu \mathrm{g} / \mathrm{m}^{3}, 130.41 \mu \mathrm{g} / \mathrm{m}^{3}$ and $0.42 \mu \mathrm{g} / \mathrm{m}^{3}, 196.74 \mu \mathrm{g} / \mathrm{m}^{3}$ and $21.72 \mu \mathrm{g} / \mathrm{m}^{3}$. The AQI values falls under poor, very poor, Moderate, Satisfactory and Severe categories. The AQI values from June to September falls under satisfactory category. The $\mathrm{PM}_{2.5}$ is critical pollutant at this location.

\section{Anand Vihar Monitoring Station}

The study shows that maximum and minimum concentration of $\mathrm{PM}_{2.5}, \mathrm{SO}_{2}$ and $\mathrm{NO}_{2}$ are 848.55 $\mu \mathrm{g} / \mathrm{m}^{3}$ and $20.84 \mu \mathrm{g} / \mathrm{m}^{3}, 607.9 \mu \mathrm{g} / \mathrm{m}^{3}$ and $4.76 \mu \mathrm{g} / \mathrm{m}^{3}, 192.13 \mu \mathrm{g} / \mathrm{m}^{3}$ and $0.24 \mu \mathrm{g} / \mathrm{m}^{3}$. The AQI values falls under poor, very poor, Moderate, Satisfactory and Severe categories. The AQI values July and August falls under satisfactory category. The $\mathrm{PM}_{2.5}$ is critical pollutant at this location.

The overall AQI of all this stations exceeds the satisfactory level value, which indicates the poor air quality.

\section{Analysis of AQI trend for different seasons:}


It was found that for all the stations the AQI values were high during winter season and low during monsoon season on account of low wind speed resulting into low dispersion air pollutants.

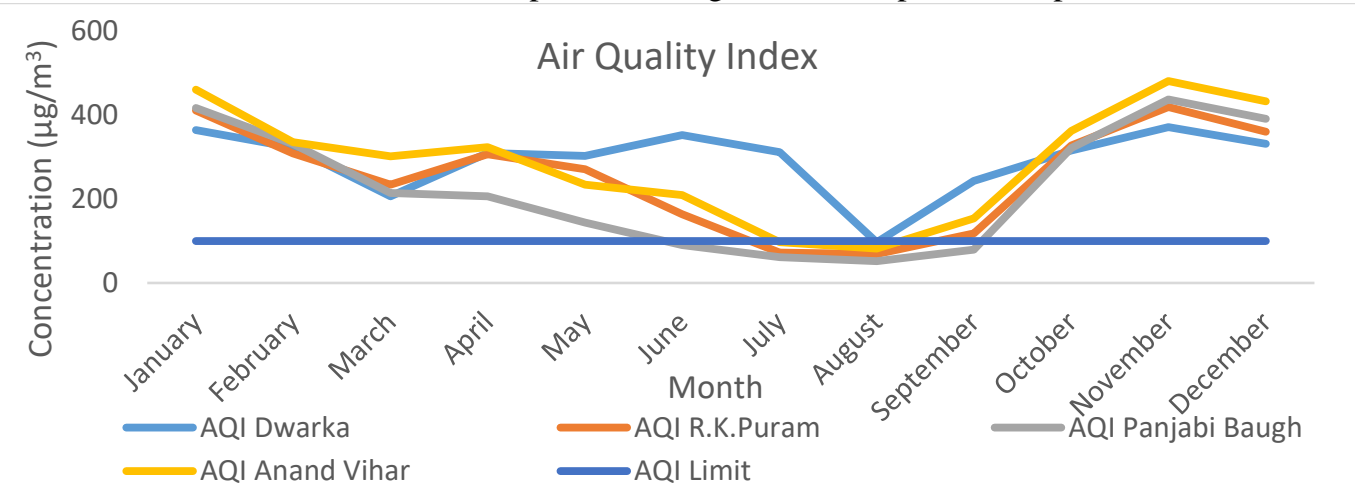

Figure 2: Variation of $A Q I$ at various locations

\begin{tabular}{|l|c|c|c|c|}
\hline \multirow{2}{*}{ Month } & \multicolumn{4}{|c|}{ AQI } \\
\cline { 2 - 5 } & & & & \\
& Dwarka & R.K Puram & Panjabi Baugh & Anand Vihar \\
\hline January & 365 & 412 & 418 & 461 \\
\hline February & 323 & 309 & 332 & 336 \\
\hline March & 207 & 235 & 215 & 302 \\
\hline April & 310 & 307 & 207 & 324 \\
\hline May & 303 & 271 & 144 & 235 \\
\hline June & 353 & 164 & 90 & 210 \\
\hline July & 312 & 73 & 62 & 97 \\
\hline August & 97 & 69 & 52 & 82 \\
\hline September & 244 & 118 & 79 & 154 \\
\hline October & 316 & 328 & 322 & 363 \\
\hline November & 372 & 420 & 438 & 482 \\
\hline December & 332 & 361 & 392 & 434 \\
\hline
\end{tabular}

Table 3: Monthly Air Quality Index Value of monitoring stations of Delhi (2016)

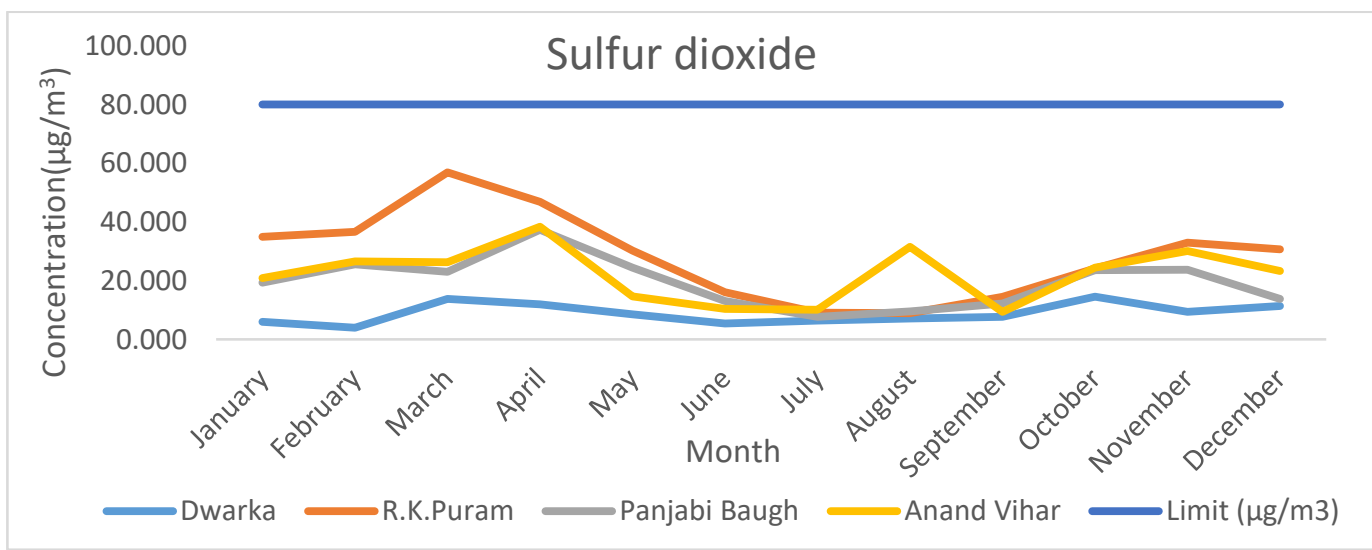

Figure 3: Monthly variation of Sulfur dioxide at various locations 


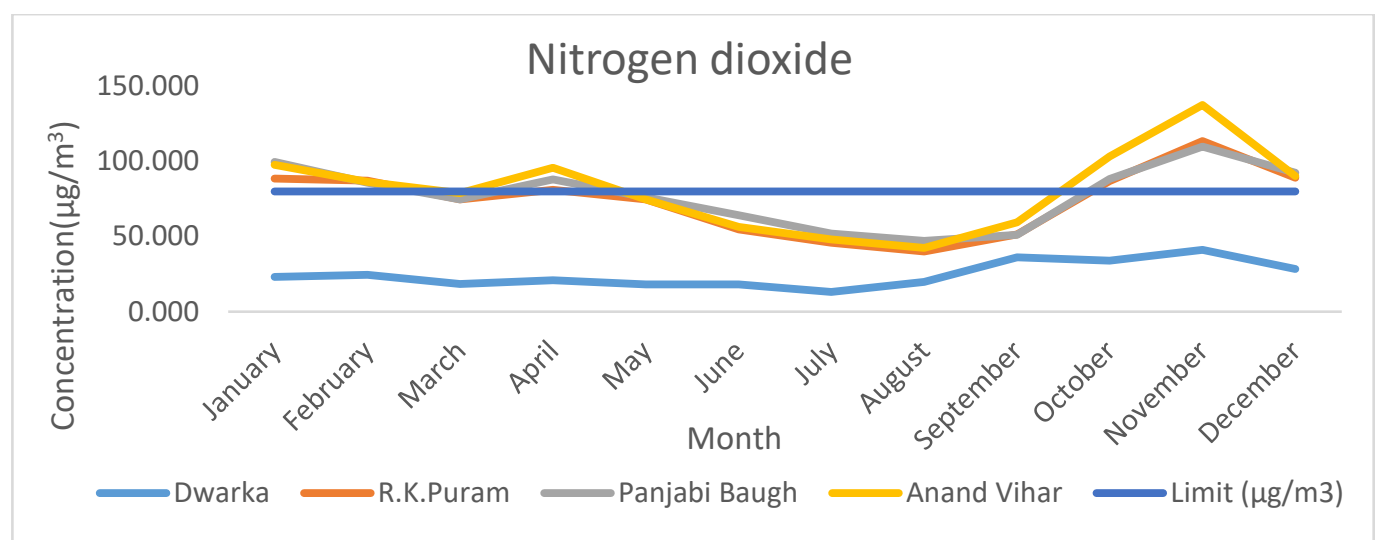

Figure 4: Monthly variation of Nitrogen dioxide at various locations

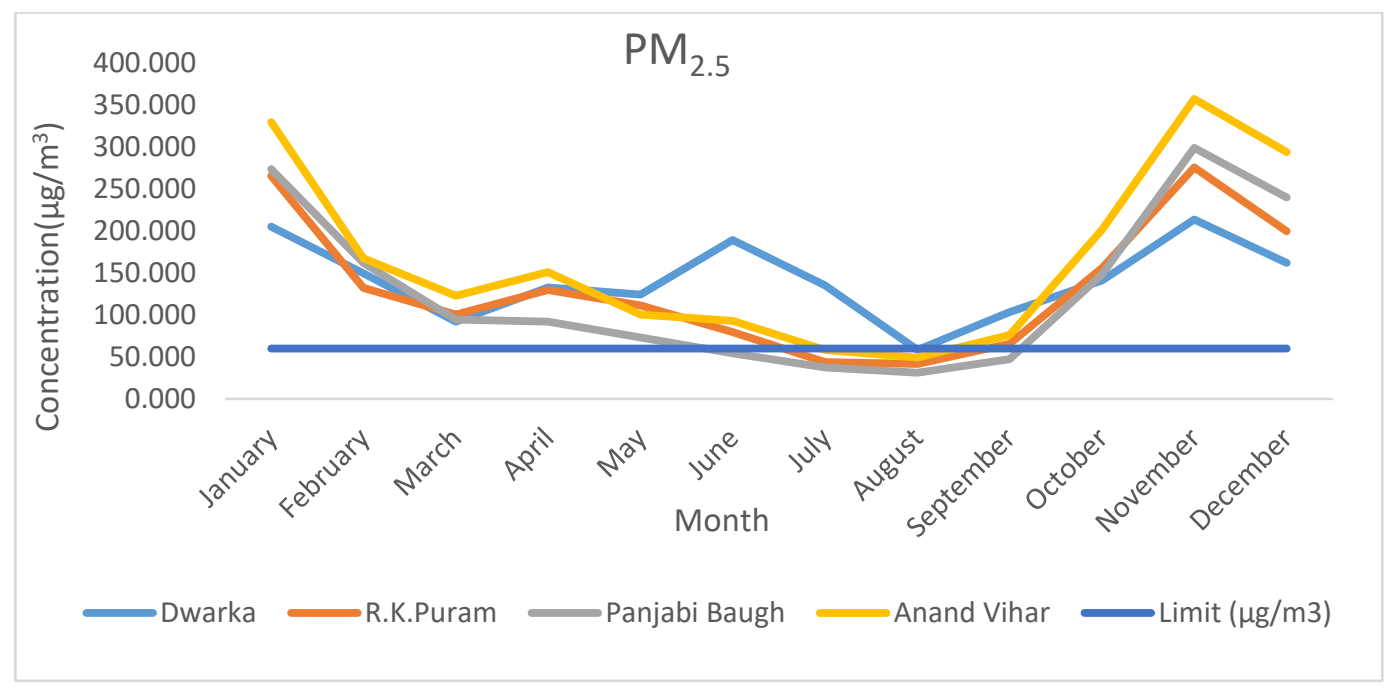

Figure 5: Monthly variation of Particulate Matter $\left(\mathbf{P M}_{2.5}\right)$ at various locations

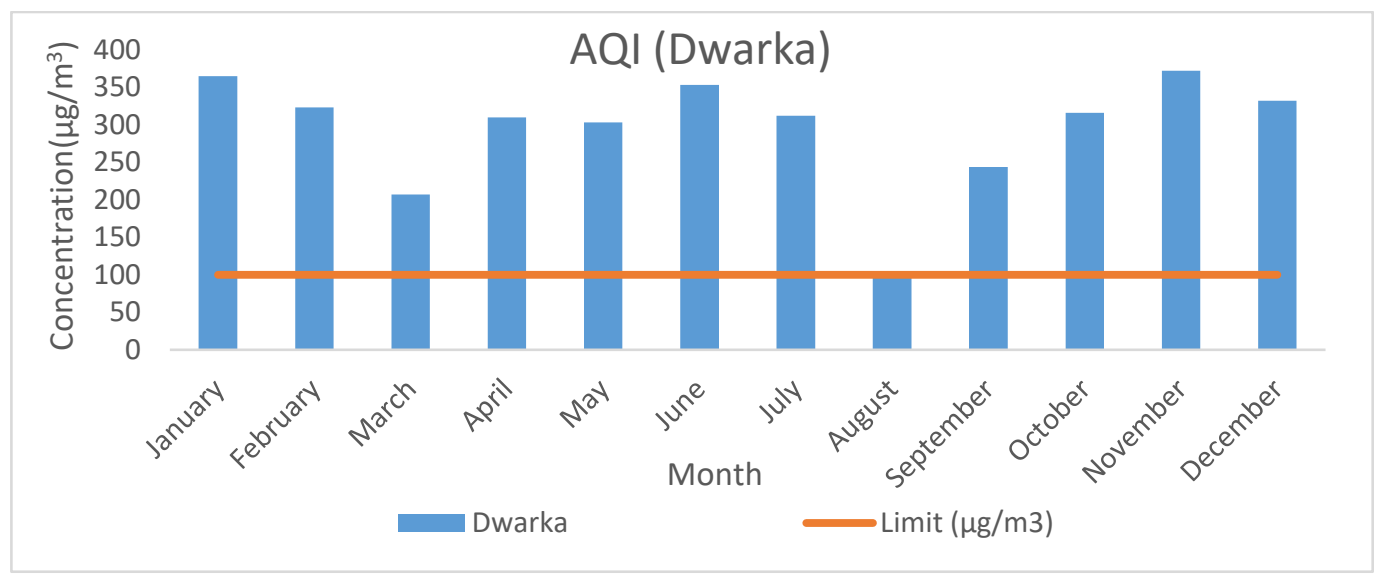

Figure 6: Variation of AQI at Dwarka 


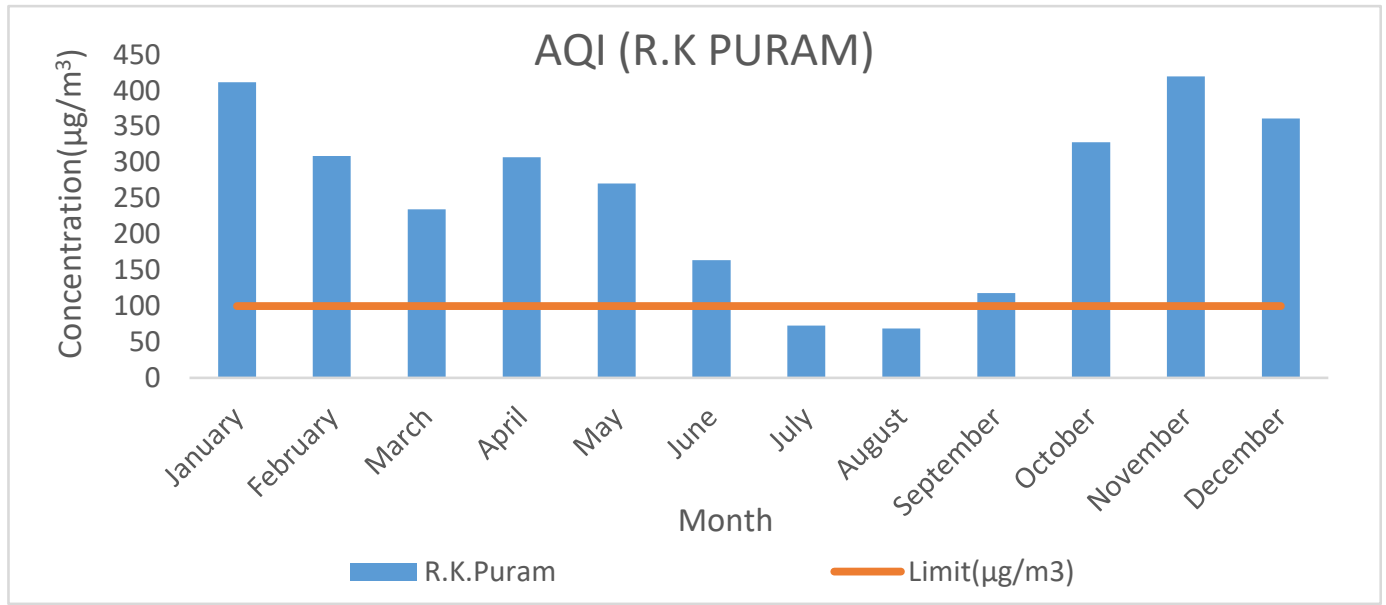

Figure 7: Variation of AQI at R.K Puram

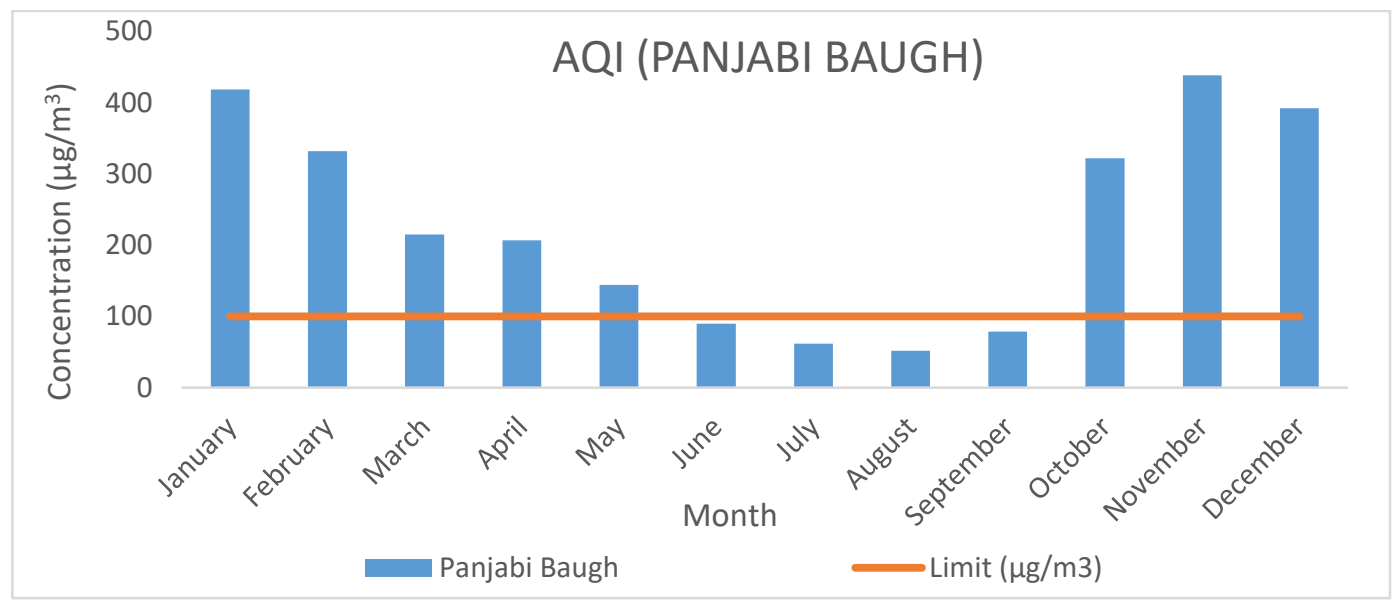

Figure 8: Variation of AQI at Panjabi Baugh

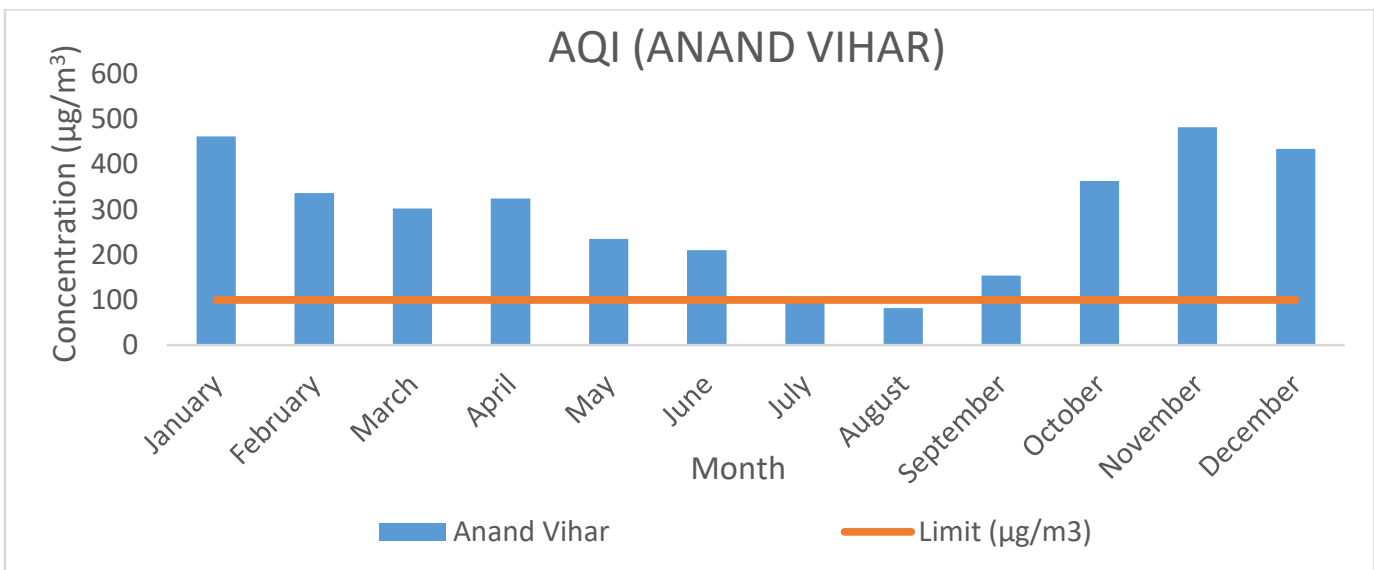

Figure 9: Variation of AQI at Anand Vihar 


\section{References}

Anand Kumar, Dr. Ashish Garg and Prof. Upender Pandel, 2011, A Study of Ambient Air Quality Status in Jaipur City (Rajasthan, India), Using Air Quality Index, Nature and Science, 9(6), 38 -43. CPCB,National Air Quality Index, 2014, (http://cpcb.nic.in/AQI-FINAL- BOOK.pdf)

Kamath, Lokeshappa, 2014, Air Quality Indexing For Selected Areas in Bangalore City, Karnataka State, India, International Journal of Innovative Research in Science,Engineering and Technology, Vol 3(8), 15625 -15630.

Kumar, A. (2005). Air pollution studies at Tughlakabad environmentally sensitive area in New Delhi. Indian J. Air Pollut. Control. 1: 86-93.

Rao, M.N., Rao, H.V.N., 1989, Air Pollution, McGraw Hill Education Private Limited, Newdelhi.

Srivastava, R.K. and Sarkar, R. (2006). Air Quality Index: A Brief Review. Indian J. Environ. Prot. 26: 344-347.

Srinivas, J., and Purushotham, A.V., 2013, Determination of Air Quality Index Status in Industrial areas of Visakhapatnam, India, Research Journal of Engineering Sciences, Vol. 2(6), 13-24. 